yet been fully explored. The aim of this retrospective, multicenter study (MITO RT-02) was to define efficacy and safety of SBRT in a very large, real life dataset of metastatic/persistent/recurrent cervical cancer (MPR-CC) patients.

Abstract 933 Table 1 Patients and treatments characteristics

\begin{tabular}{|c|c|}
\hline & N. $(\%)$ \\
\hline Patients & 84 \\
\hline Lesions & 126 \\
\hline Age, yrs & $58(30-92)$ \\
\hline \multicolumn{2}{|l|}{ Median (range) } \\
\hline ECOG Performance Status & $79(94.1)$ \\
\hline $0-1$ & $5(5.9)$ \\
\hline \multicolumn{2}{|l|}{$2-3$} \\
\hline Histotype & $77(61.1)$ \\
\hline Squamous & $36(28.6)$ \\
\hline Adenocarcinoma & $5(4.0)$ \\
\hline Adenosquamous & $3(2.4)$ \\
\hline Clear cell & $5(4.0)$ \\
\hline \multicolumn{2}{|l|}{ Other } \\
\hline N. lesions per patients & $61(72.6)$ \\
\hline 1 & $13(15.4)$ \\
\hline 2 & $10(12.0)$ \\
\hline \multicolumn{2}{|l|}{$\geq 3$} \\
\hline Type of lesion (\%) & $70(55.5)$ \\
\hline Lymph node & $46(36.5)$ \\
\hline Parenchyma & $10(8.0)$ \\
\hline \multicolumn{2}{|l|}{ Bone } \\
\hline Anatomic Site & $7(5.5)$ \\
\hline Neck & $34(27.0)$ \\
\hline Thorax & $32(25.4)$ \\
\hline Abdomen & $46(36.6)$ \\
\hline Pelvis & $7(5.5)$ \\
\hline \multicolumn{2}{|l|}{ Bone } \\
\hline Metachronous lesions & 99 (78.6) \\
\hline No & $27(21.4)$ \\
\hline \multicolumn{2}{|l|}{ Yes } \\
\hline $\mathrm{N}$. patients undergoing previous radiotherapy in site & $53(63.1)$ \\
\hline No & $31(36.9)$ \\
\hline \multicolumn{2}{|l|}{ Yes } \\
\hline Equipments & $108(85.7)$ \\
\hline INAC & $10(7.9)$ \\
\hline Cyberknife & $1(0.8)$ \\
\hline Tomotherapy & $7(5.6)$ \\
\hline \multicolumn{2}{|l|}{ MRI LINAC } \\
\hline Type of treatment & $26(20.6)$ \\
\hline SRS, stereotactic radiosurgery (single fraction) & $100(79.4)$ \\
\hline \multicolumn{2}{|l|}{ SBRT, stereotactic radiotherapy (more fractions) } \\
\hline PTV & $16.8(1.8-223.3)$ \\
\hline \multicolumn{2}{|l|}{ Median, range (cc) } \\
\hline Total dose, Gy & $35(5-60)$ \\
\hline \multicolumn{2}{|l|}{ Median (range) } \\
\hline Dose/fraction, Gy & $7(2.5-26)$ \\
\hline \multicolumn{2}{|l|}{ Median (range) } \\
\hline Dose prescription & $48(38.1)$ \\
\hline Specific isodose & $32(25.4)$ \\
\hline Isocenter & $46(36.5)$ \\
\hline Target mean & \\
\hline
\end{tabular}

Methodology Clinical and SBRT parameters have been collected in order to fulfill primary endpoints, i.e. the rate of complete response (CR) to SBRT, and the 24-month actuarial local control (LC) rate on 'per lesion' basis. The secondary end-points were acute and late toxicities. Objective response rate (ORR) included $\mathrm{CR}$ and partial response (PR). Clinical benefit (CB) included ORR and stable disease (SD). Toxicity was evaluated by RTOG/EORTC and CTC-AE scales, according to center policy.

Result(s)* Fifteen centers participated to the study; after evaluation of inclusion/exclusion criteria, 84 CC patients, carrying a total of 126 lesions treated by SBRT between March 2006 and February 2021, were selected for the analysis. Patient characteristics and treatment data are summarized in table 1. Complete and partial response, as well as stable disease were observed in 73 (57.9\%), 30 (23.8\%), and 16 (12.7\%) lesions, respectively, reaching about 94\% CB rate. With a median follow-up of 14 months (range: 3-130), the 24-month actuarial LC, DFS and OS rate were $61.8 \%$, $22.3 \%$, 52.9\%, respectively. Mild acute toxicity was experienced in $14(16.6 \%)$ patients; late toxicity was documented in 4 patients $(4.7 \%)$.

Conclusion* This study confirms the efficacy and safety of SBRT in MPR-CC patients. The low toxicity profile suggests a wider use of this treatment in this setting, however combinations with new drugs are needed to improve outcomes.

\section{ABSTRACT WITHDRAWN \\ 942 SURVIVAL AFTER RECURRENCE IN EARLY-STAGE CERVICAL CANCER PATIENTS}

${ }^{1} \mathrm{~L}$ Van Lonkhuijzen*, ${ }^{2} \mathrm{~L}$ Dostalek, ${ }^{3}$ J Jarkovsky, ${ }^{4} \mathrm{~A}$ Lopez, ${ }^{5} \mathrm{H}$ Falconer, ${ }^{6} \mathrm{G}$ Scambia, ${ }^{7} \mathrm{~A}$ Ayhan, ${ }^{8} \mathrm{~S}$ Kim, ${ }^{9} \mathrm{D}$ Isla Ortiz, ${ }^{10} \mathrm{~J}$ Klat, ${ }^{11} \mathrm{~A}$ Obermair, ${ }^{12} \mathrm{GDI}$ Martino, ${ }^{13} \mathrm{R}$ Pareja, ${ }^{14} \mathrm{R}$ Manchanda, ${ }^{15} \mathrm{~J}$ Kostun, ${ }^{16} \mathrm{R}$ Dos Reis, ${ }^{17} \mathrm{I}$ Zapardiel, ${ }^{18} \mathrm{~V}$ Weinberger, ${ }^{2} \mathrm{D}$ Cibula. ${ }^{1}$ Amsterdam UMC, locatie AMC, Gynecologic oncology, Amsterdam, Netherlands; ${ }^{2}$ First Faculty of Medicine Charles University, Gynecologic Oncology Center, Department of Obstetrics and Gynecology, Prague, Czech Republic; ${ }^{3}$ Faculty of Medicine Masaryk University, Czech Republic; ${ }^{4}$ National Institute of Neoplastic Diseases, Gynecological Surgery; ${ }^{5}$ Karolinska University Hospital, Department of Pelvic Cancer, Stockholm, Sweden; ${ }^{6}$ Fondazione Policlinico Universitario A. Gemelli, Roma, Italy; ${ }^{7}$ Başkent University, Gynecology and Obstetrics, Division of Gynecologic Oncology, Ankara, Turkey; ${ }^{8}$ Memorial Sloan Kettering Cancer Center, Department of Surgery, New York, USA; ${ }^{9}$ National Institute of Cancerology Mexico, Gynecology Oncology Center, mexico, Mexico; ${ }^{10}$ University of Ostrava - Faculty of Medicine, Obstetrics and Gynecology, Ostrava, Czech Republic; ${ }^{11}$ The University of Queensland, Queensland Centre for Gynaecological Cancer, Saint Lucia, Australia; ${ }^{12}$ Building U6 - University of Milano-Bicocca, Department of Obstetrics and Gynecology, Gynaecologic Oncology Surgical Unit, Milano, Italy; ${ }^{13}$ National Cancer Institute - ESE, Department of Gynecologic Oncology, Bogotá, Colombia; ${ }^{14}$ Queen Mary University of London, Barts Cancer Centre, UK; ${ }^{15}$ University Hospital in Pilsen, Department of Gynaecology and Obstetrics, Prague, Czech Republic; ${ }^{16}$ The University of Texas MD Anderson Cancer Center, Department of Gynecologic Oncology and Reproductive Medicine, Houston, USA; ${ }^{17}$ La Paz University Hospital, Gynecologic Oncology Unit, Madrid, Spain; ${ }^{18}$ Faculty of Medicine Masaryk University, Brno, Czech Republic

\subsection{6/ijgc-2021-ESG0.78}

Introduction/Background* Up to $26 \%$ of early-stage cervical cancer patients relapse after primary surgical treatment. However, little is known about the factors affecting prognosis 
following disease recurrence. Hence, the aim of this study was to evaluate post-recurrence disease-specific survival (PR-DSS) and to identify respective prognostic factors.

Methodology Data from 528 early-stage cervical cancer patients who relapsed after primary surgical treatment performed between 2007 and 2016 were obtained from the SCCAN study (Surveillance in Cervical CANcer). Parameters related both to primary disease and recurrence diagnosis were combined to develop a multivariable Cox proportional hazards model predicting PR-DSS.

Result(s)* Five-year PR-DSS reached 39.1\% (95\% confidence interval: $22.7 \%-44.5 \%)$ with median disease-free survival between primary surgery and recurrence diagnosis (DFI1) of
1.5 years and median survival after recurrence of 2.5 years. Six variables significant in multivariable analysis were included in the PR-DSS prognostic model; two related to the primary disease characteristics: maximal diameter of the tumour and lymphovascular space invasion; and four related to the recurrence diagnosis: DFI1, age, presence of symptoms, and recurrence localization (table 1). C-statistics of the final model after 10 -fold internal validation equalled 0.701 (95\% CI: 0.675 - 0.727). Five risk groups significantly differing in prognosis were identified, with 5 -year DSS after recurrence of $85.6 \%, 62.0 \%, 46.7,19.7 \%$, and $0 \%$ in the highest risk group (figure 1).

Abstract 942 Table 1 Multivariable Cox regression model for prediction of disease-specific death after recurrence

\begin{tabular}{|c|c|c|c|c|c|c|c|}
\hline Predictor & & B & $\operatorname{SE}(\beta)$ & HR & $95 \% \mathrm{Cl}$ & P-value & Points (max. 100) \\
\hline \multirow{2}{*}{$\begin{array}{l}\text { Years from surgery to } \\
\text { recurrence }\end{array}$} & $>1$ year & & & Reference & & & 0 \\
\hline & $<1$ year & 0.516 & 0.132 & 1.676 & $1.294-2.169$ & $<0.001$ & 11 \\
\hline \multirow[t]{2}{*}{ Age at recurrence } & $<65$ years & & & Reference & & & 0 \\
\hline & $65+$ years & 0.543 & 0.187 & 1.720 & $1.192-2.482$ & 0.004 & 12 \\
\hline Maximal pathologic & $<0.5 \mathrm{~cm}$ & & & Reference & & & 0 \\
\hline \multirow[t]{3}{*}{ tumour diameter* } & $0.5-1.9 \mathrm{~cm}$ & 0.947 & 0.602 & 2.577 & $0.792-8.380$ & 0.116 & 20 \\
\hline & $2.0-3.9 \mathrm{~cm}$ & 1.269 & 0.593 & 3.557 & $1.113-11.374$ & 0.032 & 27 \\
\hline & $\geq 4.0 \mathrm{~cm}$ & 1.481 & 0.598 & 4.397 & $1.363-14.184$ & 0.013 & 31 \\
\hline \multirow[t]{2}{*}{ LVSI* } & No/unknown & & & Reference & & & 0 \\
\hline & Yes & 0.672 & 0.148 & 1.957 & $1.463-2.619$ & $<0.001$ & 14 \\
\hline \multirow[t]{2}{*}{ Recurrence symptoms } & No & & & Reference & & & 0 \\
\hline & Yes/unknown & 0.788 & 0.151 & 2.199 & $1.634-2.958$ & $<0.001$ & 17 \\
\hline \multirow[t]{2}{*}{ Recurrence localization } & Isolated & & & Reference & & & 0 \\
\hline & Multiple & 0.687 & 0.135 & 1.987 & $1.526-2.587$ & $<0.001$ & 15 \\
\hline
\end{tabular}

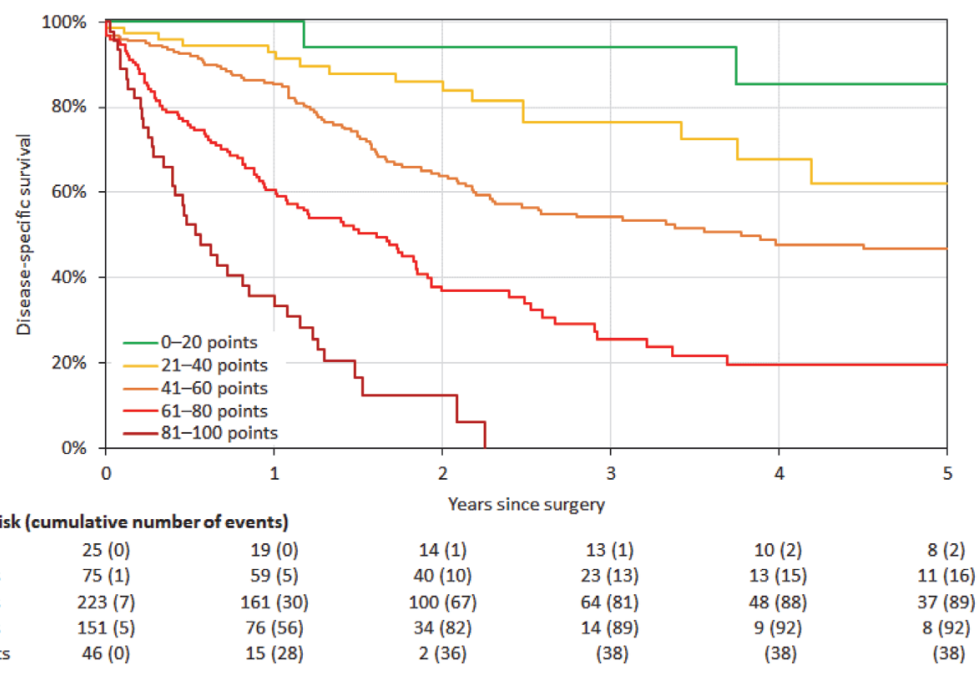

\begin{tabular}{|c|c|}
\hline $\begin{array}{l}\text { No. of } \\
\text { years }\end{array}$ & $\begin{array}{l}\text { Disease-specific survival } \\
\text { (95\% confidence interval) }\end{array}$ \\
\hline \multicolumn{2}{|c|}{$0-20$ points } \\
\hline 1 & $100.0 \%(100.0 \% ; 100.0 \%)$ \\
\hline 2 & $94.1 \%(82.9 \% ; 100.0 \%)$ \\
\hline 3 & $94.1 \%(82.9 \% ; 100.0 \%)$ \\
\hline 4 & $85.6 \%(66.6 \% ; 100.0 \%)$ \\
\hline 5 & $85.6 \%(66.6 \% ; 100.0 \%)$ \\
\hline \multicolumn{2}{|c|}{ 21-40 points } \\
\hline 1 & $92.9 \%$ (86.8\%; 98.9\%) \\
\hline 2 & $83.8 \%(74.4 \% ; 93.2 \%)$ \\
\hline 3 & $76.3 \%(64.5 \% ; 88.1 \%)$ \\
\hline 4 & $67.7 \%(52.2 \% ; 83.1 \%)$ \\
\hline 5 & $62.0 \%(44.3 \% ; 79.7 \%)$ \\
\hline \multicolumn{2}{|c|}{ 41-60 points } \\
\hline 1 & $85.3 \%(80.5 \% ; 90.2 \%)$ \\
\hline 2 & $63.9 \%(56.9 \% ; 71.0 \%)$ \\
\hline 3 & $54.2 \%(46.6 \% ; 61.8 \%)$ \\
\hline 4 & $47.8 \%$ (39.7\%; 55.8\%) \\
\hline 5 & $46.7 \%$ (38.5\%; 54.8\%) \\
\hline \multicolumn{2}{|c|}{ 61-80 points } \\
\hline 1 & $60.6 \%(52.5 \% ; 68.6 \%)$ \\
\hline 2 & $36.8 \%(28.1 \% ; 45.6 \%)$ \\
\hline 3 & $25.4 \%$ (16.1\%; 34.8\%) \\
\hline 4 & $19.7 \%(10.5 \% ; 28.9 \%)$ \\
\hline 5 & $19.7 \%(10.5 \% ; 28.9 \%)$ \\
\hline \multicolumn{2}{|c|}{$81-100$ points } \\
\hline 1 & $35.7 \%$ (21.4\%; $50.1 \%)$ \\
\hline 2 & $12.3 \%(0.8 \% ; 23.8 \%)$ \\
\hline 3 & $0.0 \%(0.0 \% ; 0.0 \%)$ \\
\hline 4 & $0.0 \%(0.0 \% ; 0.0 \%)$ \\
\hline 5 & $0.0 \%(0.0 \% ; 0.0 \%)$ \\
\hline
\end{tabular}

Abstract 942 Figure 1 Disease specific survival of all patients stratified by risk score $(\mathrm{N}=528)$. Time zero was set at date of recurrence diagnosis 
Conclusion* We have developed the first robust model of disease-specific survival after recurrence stratifying relapsing cervical cancer patients according to their risk profile using six traditional prognostic markers. The strongest factor related to the length of post-recurrence survival was the largest size of the primary tumour, followed by the presence of symptoms at the time of diagnosis, which remained significant even after correction for lead-time bias.

\section{SENSITIVITY AND FALSE NEGATIVITY OF SLN FROZEN SECTIONHISTOLOGICAL EVALUATION IN THE SENTIX TRIAL (CEEGOG-CX01; ENGOT-CX2; NCT02494063)}

${ }^{1} \mathrm{R}$ Kocian*, ${ }^{2} \mathrm{C}$ Kohler, ${ }^{1} \mathrm{~S}$ Bajsová, ${ }^{1} \mathrm{~S}$ Sebestova, ${ }^{3} \mathrm{I}$ Zapardiel, ${ }^{4} \mathrm{GDI}$ Martino, ${ }^{5} \mathrm{~L}$ Van Lonkhuijzen, ${ }^{1} \mathrm{~B}$ Sehnal, ${ }^{3} \mathrm{O}$ Arencibia Sanchez, ${ }^{3} \mathrm{~B}$ Gil-Ibanez, ${ }^{4} \mathrm{~F}$ Martinelli, ${ }^{1} \mathrm{~J}$ Presl, ${ }^{1} \mathrm{~L}$ Minar, ${ }^{1} \mathrm{R}$ Marek, ${ }^{6} \mathrm{P}$ Kascak, ${ }^{1} \mathrm{P}$ Havelka, ${ }^{1} \mathrm{M}$ Michal, ${ }^{7} \mathrm{~T}$ Van Gorp, ${ }^{1} \mathrm{~K}$ Nemejcova, ${ }^{1}$ D Cibula. ${ }^{1}$ Czech Republic; ${ }^{2}$ Germany; ${ }^{3}$ Spain; ${ }^{4}$ Italy; ${ }^{5}$ Netherlands; ${ }^{6}$ Slovakia; ${ }^{7}$ Belgium

\subsection{6/ijgc-2021-ESGO.79}

Introduction/Background* SENTIX is a prospective cohort multicentric international study on sentinel lymph node (SLN) biopsy without pelvic lymph node dissection (PLND) in patients with early-stage cervical cancer. SLN frozen section (FS) and pathological ultrastaging were mandatory by the protocol. Samples from SLN were reviewed centrally for pathological assessment quality control. Only sites experienced in SLN biopsy technique could join the trial.

Methodology In total, 47 sites from 18 countries participated in the trial. Patients with FIGO 2009 stages T1A1/LVSI+ T1B1 $(<4 \mathrm{~cm}$ or $\leq 2 \mathrm{~cm}$ for fertility sparing), with common tumour types and no suspicious lymph nodes on imaging were

\section{Abstract 950 Table 1 Patient's characteristics $(\mathrm{N}=733)$}

\begin{tabular}{|c|c|c|}
\hline \multicolumn{2}{|l|}{ Parameter } & \multirow{2}{*}{$\begin{array}{c}\begin{array}{c}\mathrm{N}(\%) / \text { median }\left(5-95^{\text {th }}\right. \\
\text { percentile) }\end{array} \\
43(29 ; 67)\end{array}$} \\
\hline Age & & \\
\hline & $\leq 40$ & $294(40.1 \%)$ \\
\hline & $41-60$ & $339(46.2 \%)$ \\
\hline & $61+$ & $100(13.6 \%)$ \\
\hline \multirow[t]{4}{*}{ BMI } & $\leq 25$ & $418(57.0 \%)$ \\
\hline & $25-30$ & $169(23.1 \%)$ \\
\hline & $30+$ & $141(19.2 \%)$ \\
\hline & NA & $5(0.7 \%)$ \\
\hline \multirow[t]{2}{*}{ ECOG PS } & 0 & $704(96.0 \%)$ \\
\hline & 1 & $29(4.0 \%)$ \\
\hline \multirow[t]{3}{*}{ Diagnostic method } & Biopsy & $331(45.2 \%)$ \\
\hline & Conization & $399(54.4 \%)$ \\
\hline & NA & $3(0.4 \%)$ \\
\hline \multicolumn{3}{|c|}{ Enrolled patients by site's size: } \\
\hline & $\leq 10$ & $126(17.2 \%)$ \\
\hline & $21-20$ & $81(11.1 \%)$ \\
\hline & $21+$ & $526(71.8 \%)$ \\
\hline \multirow{2}{*}{$\begin{array}{l}\text { Maximum preoperative } \\
\text { tumour size }(\mathrm{mm})\end{array}$} & $\leq 20$ & $471(64.2 \%)$ \\
\hline & $20.1-40$ & $262(35.8 \%)$ \\
\hline Preoperative tumour stage & $1 \mathrm{~A} 1$ & $32(4.4 \%)$ \\
\hline \multirow[t]{2}{*}{ (FIGO 2009) } & $1 \mathrm{~A} 2$ & $54(7.4 \%)$ \\
\hline & 1B1 & $647(88.2 \%)$ \\
\hline \multirow[t]{4}{*}{ Tumour grade } & G1 & $179(24.4 \%)$ \\
\hline & G2 & $373(50.9 \%)$ \\
\hline & G3 & $157(21.4 \%)$ \\
\hline & NA & $24(3.3 \%)$ \\
\hline LVSI & yes & $448(61.1 \%)$ \\
\hline \multirow[t]{4}{*}{ Tumour type } & SCC & $508(69.3 \%)$ \\
\hline & $A C$ & $210(28.6 \%)$ \\
\hline & AS & $9(1.2 \%)$ \\
\hline & NA & $6(0.8 \%)$ \\
\hline Excluded: & & $83(11.2 \%)$ \\
\hline \multirow{2}{*}{ Preoperatively } & Surgery cancelled & $4(0.5 \%)$ \\
\hline & ICF withdrawn & $4(0.5 \%)$ \\
\hline \multirow[t]{2}{*}{ Intraoperatively } & SLN not detected bilaterally & $55(7.5 \%)$ \\
\hline & $>1 \mathrm{~B} 1$ & $12(1.6 \%)$ \\
\hline Other & & $8(1.1 \%)$ \\
\hline
\end{tabular}

Abstract 950 Table 2 SLN status assessed by frozen section and final ultastaging $(\mathrm{N}=650)$

\begin{tabular}{ccccccc}
\hline \hline \multirow{2}{*}{$\begin{array}{c}\text { Type of SLN } \\
\text { involvement }\end{array}$} & \multicolumn{2}{c}{ SLN status (No. of patients) } & \multicolumn{4}{c}{ SLN frozen section outcome (\%) } \\
\cline { 2 - 7 } & $\begin{array}{c}\text { Frozen } \\
\text { section }\end{array}$ & Ultrastaging & $\begin{array}{c}\text { Final SLN } \\
\text { status* }\end{array}$ & Sensitivity & $\begin{array}{c}\text { False } \\
\text { negativity }\end{array}$ & NPV \\
\hline MAC & 44 & 9 & 53 & $83.0 \%$ & $17.0 \%$ & $98.5 \%$ \\
MIC & 4 & 26 & 30 & $13.3 \%$ & $86,7 \%$ & $95.7 \%$ \\
ITC & 0 & 19 & 19 & $0.0 \%$ & $100,0 \%$ & $96.8 \%$ \\
MAC + MIC & 48 & 35 & 83 & $57.8 \%$ & $42,2 \%$ & $94.2 \%$ \\
MAC + MIC + ITC & 48 & 54 & 102 & $47.1 \%$ & $52.9 \%$ & $91.0 \%$ \\
\hline
\end{tabular}

registered in the trial. Patients remained in the trial after the surgery if SLN were detected on both sides of the pelvis and if SLN were negative on FS histological evaluation. Blue dye, radioactive tracer, indocyanine green or their combinations were all eligible tracers for SLN detection. Intraoperative SLN pathological processing consisted of SLN examination in one randomly selected slice. SLN ultrastaging protocol included a complete processing of all SLN tissue in slices of $2 \mathrm{~mm}$ thickness, 2 sections in $150 \mu \mathrm{m}$ from each block until no tissue left, one stained with H\&E and second examined immunohistochemically.

Result(s)* Altogether 733 patients were registered until Sentix enrolment closure in October 2020, 83 patients were excluded (table 1) and 650 patients was analysed. Patients` characteristics are shown in table 1 . Bilateral SLN detection rate reached 95\%. FS detected macrometastases (MAC) in 44 cases and micrometastasis (MIC) in 4 cases. SLN ultrastaging found additional 9 cases with MAC, 26 with micrometastases (MIC) and all 19 cases with isolated tumor cells (ITC). Sensitivity of FS was $83.0 \%$ for the detection of MAC, $57.8 \%$ for $\mathrm{pN} 1$ status (MAC or MIC) and $47.1 \%$ for any type of SLN involvement (MAC, MIC, ITC). Table 2.

Conclusion* High bilateral detection rate of $95 \%$ was achieved in Sentix sites experienced in the SLN biopsy technique. Intraoperative pathological assessment of SLN failed to detect majority of MIC (86.7\%), all cases with ITC and $42.2 \%$ with pN1 (MIC or MAC).

\section{WATER-JET DISSECTION IN NERVE-SPARING RADICAL HYSTERECTOMY: POSTOPERATIVE OUTCOMES}

S Mukhtarulina*, M Meshkova, O Trushina, H Maltsagova, E Novikova. P.A. Hertsen Moscow Oncology Research Center - branch of FSBI NMRRC, the department of gynecologic oncology, Moscow, Russian Federation

\subsection{6/ijgc-2021-ESG0.80}

Introduction/Background* The development of a nerve-sparing technique of radical hysterectomy leads to a significant functional improvement after surgical treatment of cervical cancer. However, the risk of nerve fibers damage remains high because of difficulties in recognition of elements of the autonomic nervous system. One of approaches for precise nerve dissection is tissue-selective dissection with a water-jet. The main advantage of this method is selective dissection and preservation of nerve fibers and vessels with minimal deformation of the surrounding tissue. This study was aimed to evaluate 